\title{
Pentalogy of Cantrell with Sternum Agenesis-A Case Report
}

\author{
Elias Amorim¹, Nilo Antunes Sousa Filho', Petrucio Abrantes Sarmento², Joseval Silva Lacerda ${ }^{3}$, \\ Wildel Campos Ferreira33, Paulo Roberto Mocelin', Antonio Vieira Dias Filho4, \\ Victor Hugo Dorigo Castilho5 ${ }^{5}$ Joel Fernando Sodré Bayma Silva ${ }^{6}$, Rejane Albuquerque 7 , \\ Camila Raposo ${ }^{7}$, Marineia Vale ${ }^{7}$
}

\footnotetext{
${ }^{1}$ Thoracic Surgery Service of the Teaching Hospital of the Federal University of Maranhão, Maranhão, Brazil

${ }^{2}$ Thoracic Surgery Service of the Teaching Hospital of the Federal University of Paraiba, Paraiba, Brazil

${ }^{3}$ Cardiac Surgery Service of the Teaching Hospital of the Federal University of Maranhão, Maranhão, Brazil

${ }^{4}$ Plastic Surgery Service of the Teaching Hospital of the Federal University of Maranhão, Maranhão, Brazil

${ }^{5}$ Anesthesiology Service of the Teaching Hospital of the Federal University of Maranhão, Maranhão, Brazil

${ }^{6}$ Medical Student-Researcher of the Teaching Hospital of the Federal University of Maranhão, Maranhão, Brazil

${ }^{7}$ Intensive Therapy Service of the Teaching Hospital of the Federal University of Maranhão, Maranhão, Brazil

Email: amorimelm@gmail.com
}

How to cite this paper: Amorim, E., Filho, N.A.S., Sarmento, P.A., Lacerda, J.S., Ferreira, W.C., Mocelin, P.R., Filho, A.V.D., Castilho, V.H.D., Silva, J.F.S.B., Albuquerque, R., Raposo, C. and Vale, M. (2020) Pentalogy of Cantrell with Sternum Agenesis-A Case Report. Open Journal of Thoracic Surgery, 10, 1-5.

https://doi.org/10.4236/ojts.2020.101001

Received: September 19, 2019

Accepted: January 17, 2020

Published: January 20, 2020

Copyright $\odot 2020$ by author(s) and Scientific Research Publishing Inc. This work is licensed under the Creative Commons Attribution International License (CC BY 4.0).

http://creativecommons.org/licenses/by/4.0/

(c) (i) Open Access

\begin{abstract}
Introduction: Pentalogy of Cantrell is a rare disorder described by Cantrell in 1958 and characterized by heart anomalies, involving defects of the diaphragm, abdominal wall, supraumbilical region and pericardium. Methods: We report a case of the disease that presented with agenesis of the sternum and partial absence of costal cartilage, treated by a multi-disciplinary team. Results: The patient underwent median sternotomy. An enlarged heart, compromising the pulmonary trunk and the right ventricle, and a left superior vena cava were identified. The right atrium was opened and an interventricular communication of around $10 \mathrm{~mm}$ in diameter was seen through the tricuspid valve. Following the repair of the heart defects, chondroplasty and placement of biological mesh (Bioway of Gore) were performed. Conclusion: A Successful surgical treatment for Cantrell Syndrome includes correction of the cardiac malformation, a good repair of thoracoabdominal wall.
\end{abstract}

\section{Keywords}

Pentalogy of Cantrell, Agenesis, Diaphragm, Pericardium

\section{Introduction}

The entitled syndrome of Cantrell is detected at birth, and was first described by Cantrell in 1958, constituting, until today a surgical challenge for the complexity 
of the congenital malformations, and included the presence of five main malformations: upper abdominal wall abnormality, sternal defect, anterior diaphragmatic defect, pericardium defect, and congenital heart abnormalities [1]. It is a rare congenital anomaly that often has a poor prognosis [2].

The frequency of this malformation has been described in the literature in 1 for every 65,000 - 200,000 births. The defect expression may vary and prognosis depends on severity of the lesions. However, patients with ectopiacordis usually have a high perinatal rate. Some cases of Cantrell's pentalogy have been etiologically associated with chromosomal abnormalities, as chromosome 18 trisomy. However, in most cases, the origin of the defect is not known [3].

In the present study, we describe a case of sternum agenesis.

\section{Case Report}

We describe a case of a 5-month-old infant with Pentalogy of Cantrell involving agenesis of the sternum and a portion of the costal cartilages (Figure 1), and ectopic heart covered with partially necrotic skin (Figure 2). The echocardiogram disclosed a $15 \mathrm{~mm}$ entry type interventricular communication (IVC) and patent foramen ovale.

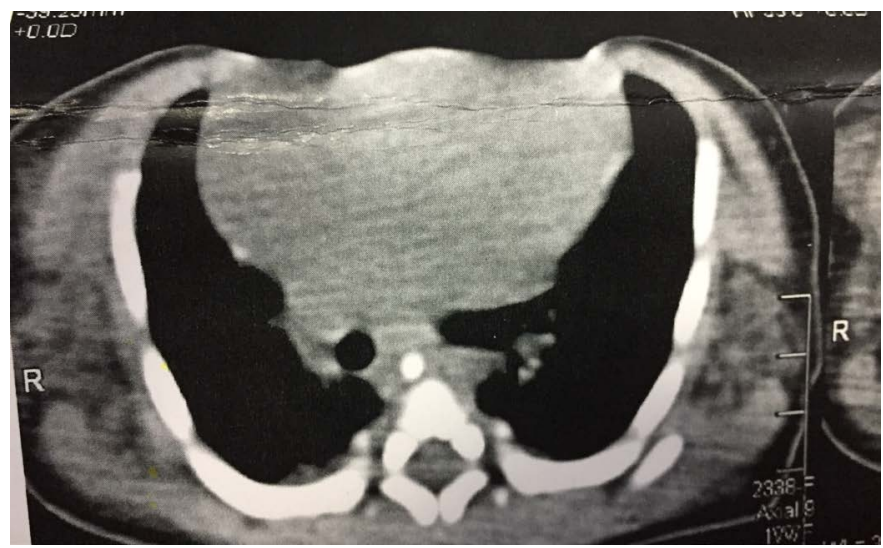

Figure 1. Absence of the sternum.

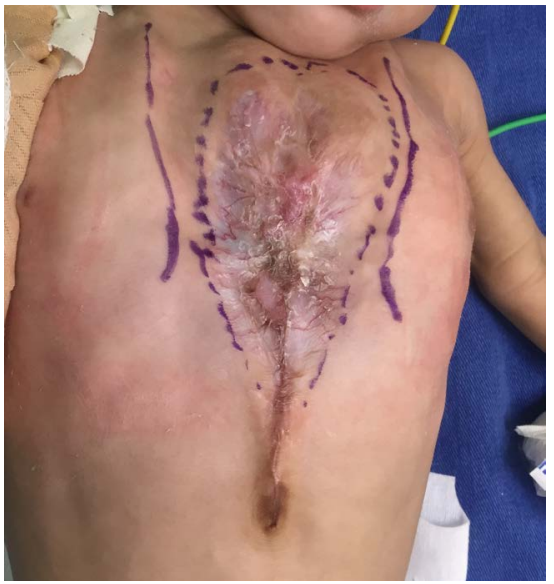

Figure 2. Necrotic skin. 


\section{Surgical Technique}

The patient underwent a median sternotomy. An enlarged heart, compromising the pulmonary trunk and the right ventricle, and a left superior vena cava were identified. Under heparinization, extracorporeal circulation (ECC) was established by cannulation of the aorta and superior an inferior vena cava, followed by cardioplegic heart arrest.

The right atrium was opened and an interventricular communication of around $10 \mathrm{~mm}$ in diameter was seen through the tricuspid valve. The defect was repaired using a bovine pericardial patch sutured with Ethibond 4-0 suture without Teflon; the patent foramen ovale was repaired with a " $U$ " stitch using Prolene 5-0; (Figure 3) right atrium closure was performed on a double-plane with Prolene 6-0 suture; air was removed from heart cavities and ECC discontinued. $\mathrm{EEC}$ time $=70 \mathrm{~min}$.

Following the repair of the heart defects, chondroplasty and placement of biological mesh (Bioway of Gore) were performed.

Chondroplasty of existing left and right cartilages was performed by longitudinal incision for lengthening. Ribcage approximation was carried out using Ethibond 2 suture until parameters of flow volume, MAP, CVP, plateau pressure and airway pressure were stabilized. Longitudinal placement of Bioway-core mesh on pre-pericardial plane beneath chondral cartilage for posterior reinforcement.

Separate Ethibond stitches, ensuring $02 \mathrm{~cm}$ spacing between costal cartilage ends.

For Mediastinal drainage was used a $16 \mathrm{Fr}$ tube.

After the procedures, the patient was placed in the intensive care unit (ICU).

The patient was intubated for 5 days and discharged from hospital on the 35th post-operative day.

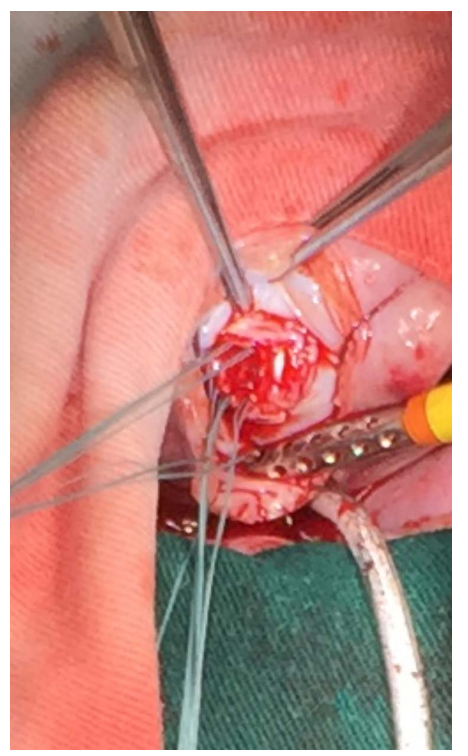

Figure 3. Patent foramen ovale. 


\section{Discussion}

In 1958, Cantrell et al. reported 5 cases of children with ectopiacordis associated with diaphragmatic hernia, partial pericardium, defects in the ventricular septum and part of the sternum [2].

The authors attributed the cause to embryonic developmental defects between the 14th and 19th days of embryonic life [3].

Pentalogy of Cantrell syndrome is more prevalent in males (57.5\%) and has an estimated incidence of 1:65,000 live births [4] [5] [6].

Hazin et al. reported surgical planning in two stages: initial repair of the diaphragmatic defect, omphalocele and left ventricle diverticulum if present, and subsequent correction of heart defects [7].

The patient reported underwent one-stage surgical treatment.

Many materials have been developed for repairing these defects, but the use of autologous tissues is preferable [8].

The present case involved agenesis of the sternum and therefore a biological mesh (Bioway) was employed.

\section{Conclusions}

A Successful surgical treatment for Cantrell Syndrome includes correction of the cardiac malformation, a good repair of thoracoabdominal wall, use of biological mesh in the sternum, complete repair of diaphragm and pericardium.

And if possible, as in this case, it was in a single surgical time.

The follow-up is being done on an outpatient basis every two months, and so far has no abnormalities.

\section{Conflicts of Interest}

The authors declare no conflicts of interest regarding the publication of this paper.

\section{References}

[1] Cantrell, J.R., Haller, J.A. and Ravitsh, M.M. (1958) A Syndrome of Congenital Defects Involving the Abdominal Wall, Sternum Diaphragm, Pericardium and Heart. Surgery, Gynecology \& Obstetrics, 107, 602-614.

[2] Pachoa, H., Barragán, A., Potes, A., Torres, J. and Isaza, C. (2010) Pentalogy of Cantrell: Report of a Case with Consanguineous Parents. Biomédica, 30, 473-477. https://doi.org/10.7705/biomedica.v30i4.284

[3] Madi, J.M., Festugatto, J.R., Rizzon, M., Agostini, A.P., Araújo, B.F., Garcia, R.M.R. (2019) Ectopia Cordis Associated with Pentalogy of Cantrell-A Case Reporter. Revista Brasileira de Ginecologia e Obstetricia, 41, 352-356. https://doi.org/10.1055/s-0039-1679878

[4] Vazquez-Jimenez, J.F., Muehler, E.G., Daebritz, S., Keutel, J., Nishigaki, K., Huegel, W. and Messmer, B.J. (1998) Cantrell's Syndrome: A Challenge to the Surgeon. The Annals of Thoracic Surgery, 65, 1178-1185. https://doi.org/10.1016/S0003-4975(98)00089-7 
[5] Yang, Y., Jiang, Z. and Ding, F. (2016) One-Stage Surgical Treatment for Cantrell Syndrome without Repairing the Left Ventricular Diverticulum: A Case Report. Cardiology in the Young, 26, 191-193. https://doi.org/10.1017/S104795111500030X

[6] Alencar, J.L., Falcão, A., Falcão, S.N.R., Sawicki, W.C., Liberatori, A.W. and Lopes, AC. (2000) Sindrome de Cantrell. Relato de Caso em Adulto. Arquivos Brasileiros de Cardiologia, 75, 323-325. https://doi.org/10.1590/S0066-782X2000001000007

[7] Hazin, S., Vieira, J., Gomes, S., Tenório, E., Moraes Neto, F., Lapa, C., Mattos, S. and Moraes, C.R. (1995) Pentalogia de Cantrell: Relato de Caso. Brazilian Journal of Cardiovascular Surgery, 10, 211-213.

https://doi.org/10.1590/S0102-76381995000400007

[8] Qin, T., Liu, Y.B. and Yong, A. (2016) Repair of Inferior Sternal Cleft Using a Titanium Plate in An Infant with Pentalogy of Cantrell. Journal of Cardiac Surgery, 31, 700-702. https://doi.org/10.1111/jocs.12847 